Article

\title{
Improving the Accessibility of the Tourism Industry in New Zealand
}

\author{
Cheryl Cockburn-Wootten ${ }^{1, *}$ and Alison McIntosh ${ }^{2}$ (D) \\ 1 Waikato Management School, University of Waikato, Hamilton 3216, New Zealand \\ 2 School of Hospitality \& Tourism, AUT University, Auckland 1010, New Zealand; alison.mcintosh@aut.ac.nz \\ * Correspondence: cwootten@waikato.ac.nz; Tel.: +64-7-83-8-44-66 (ext. 9252)
}

Received: 10 November 2020; Accepted: 10 December 2020; Published: 15 December 2020

\begin{abstract}
Internationally, the accessible tourism market has been identified as a growing segment that could lead the way for social inclusiveness, as well as providing the industry with financial gains and destination competitiveness. Despite the increased number of people who travel with access requirements, the sector still lacks an understanding of the expectations and experiences of access tourists. Accessible tourism covers an array of impairments from people who are immobile, visually impaired, an invisible impairment, parents with pushchairs, and seniors. The purpose of this study was to understand the expectations and experiences of the access consumer to suggest improvements for accessibility for the New Zealand tourism sector. The social model of disability was adopted to examine the sector and framed the semi-structured interviews with access consumers. Key results identified from the data were the need to achieve dignity in service offerings to gain experiences that facilitate independence and equity of access, access to information before the travel that is clear and accurate to aid planning, and accessible transport and education. In conclusion, the paper calls for the New Zealand tourism industry to align with the Disability Strategy sustainability goals to achieve equity and inclusion and create enjoyable accessible experiences in their tourist offerings.
\end{abstract}

Keywords: accessibility; New Zealand; tourism; lived experiences; dignity; tourism communications and information; transport; tourism education

\section{Introduction}

Tourism is usually viewed as a pleasurable activity. Yet, for people with access needs, it can be a site of inequalities and frustration. Internationally, the accessible tourism market has been identified as a growing segment that could lead the way for social inclusiveness, as well as providing the industry with financial gains and destination competitiveness [1,2]. The term accessible tourism relates to activities that people can freely select to join and are able to enjoy regardless of any disability, health issue, impairment, functioning abilities, or physiological imperatives [3]. Previous scholars from tourism [3,4] and economic studies [5] have concluded that the accessible tourism market is a significant and profitable area but is consistently ignored by the tourism industry. It has been estimated that more than 500 million people around the world identify themselves as having a disability or an access requirement [5]. In Europe, for instance, a Spanish study illustrated that access tourists spend more, they tend to travel with companions (resulting in a double spend) and have the possibility of generating at least 2.4 billion for the Spanish tourist industry [5]. Examples from New Zealand also illustrate the potential of this segment. For example, Statistics New Zealand in 2013 found that 24\% of people identified with a disability, and this was a significant increase from previous years and represents the possible domestic tourism market available [6]. 
Despite these economic and social change opportunities, the basic tourism service expectations of people with access requirements are not being met, or even aligning with the 2030 UNWTO tourism sustainability goals for the tourism industry [7]. There remains no access agenda within the New Zealand tourism strategy despite the potential of the access tourism market. Internationally, tourism researchers have also noted that the industry tends to be reluctant to communicate with the access market, as they often perceive the access tourist as difficult and expensive to accommodate [8]. It is also clear that the myths perpetuated within the industry about access tourists as not interested in travelling or having the financial means to engage in tourism or being difficult to accommodate are all unwarranted. An agenda to make New Zealand tourism more accessible is thus warranted.

The term 'accessible' relates to broader and inclusive concepts than the words disability or impairments [9]. Accessibility includes seniors, visual needs, intellectual disabilities, parents with pushchairs and temporary impairments. In addition, there is a $59 \%$ chance that anyone over the age of 65 years will face some kind of impairment that limits their everyday activities [6]. The term disability has been critiqued, as it is regularly over-used and can have negative connotations that tend to homogenize and generalize people with access needs [9]. The term disability enhances two problems and myths. Firstly, the label can be restrictive, as the general public tend to think that the term only applies to a person in a wheelchair and then consider physical barriers as the main problem. Many disabilities and access needs are broader and are not always visible such as intellectual, pain, hearing, and vision impairments. Secondly, the label can be viewed as offensive, as it places the responsibility or deficit on the individual rather than considering the way in which wider society structures policies, physical spaces, language, communications, and institutions. The disability label emphases the condition and places responsibility on the person before considering wider inferences [3,9].

The purpose of this paper is to report on the tourism experiences of people living in New Zealand with an access requirement. The aim was to understand the expectations and experiences of the access consumer to suggest improvements for accessibility of the New Zealand tourism sector. Many people in the industry consider the access tourists' needs as expensive to accommodate or only focus on the physical barriers that need to be removed $[9,10]$. For many access travelers, having tourist organizations and destinations meet their basic essential requirements can be a struggle [10-12]. In this paper, we identify the service expectations of access tourists and how the industry could alter their offerings to create inclusive tourism offerings that meet and perhaps even exceed these expectations. The paper will first provide some key background information regarding disability, impairment, inclusion, and accessibility. Following this section, relevant literature will discuss examples of best practice. The final sections of the paper draw on our New Zealand data to provide qualitative examples of access tourists' expectations and experiences.

\section{Background and Literature Review}

Disability is defined as the process that happens when one group of people create barriers and inequalities of access to another group by designing a world for their way of living, taking no account of the impairments other people may have in society $[6,13]$. In an equal and democratic society, people who live with an access requirement should have the same opportunities as those who are able bodied, as they too aspire to live and have a good life [14]. Society is built in a way that assumes we can all see signs, read directions, hear announcements, reach buttons, have the strength to open heavy doors, and have stable moods and perceptions [11,13]. It is with this knowledge that New Zealand has established a disability strategy to ensure an inclusive society. New Zealand aims for people who have access requirements to be able to say that they live in "a society that highly values our lives and continually enhances our full participation" [15] (p. 1).

In New Zealand, around one million people have a physical impairment, learning disability, age-related need, short term impairment, or access need [11]. This equates to about one in four of New Zealand's population identifying as disabled, which was a significant increase from the $21 \%$ in 
2001 [11]. There is a $59 \%$ chance of people who are aged 65 or over are more likely to be disabled rather than adults under 65 years of $21 \%$ or children under 15 years $11 \%$ [6]. It is clear from these statistics that a significant and rapidly increasing proportion of New Zealand's population is now in the senior older age groups, with these age groups more likely to experience disability compared to younger adults or children.

The New Zealand Disability Strategy (2016-2026) aims to ensure a long-term approach for developing partnerships for transformative initiatives that create an inclusive society [16]. The strategy was developed through collaboration, participation, and feedback from a range of stakeholders, including people with access requirements, organizations within the disability sector, education, local government, health sectors, and private sector businesses. The 2016-2026 strategy has moved away from an orientation that focused on barriers to instead aiming for equity, improvements, opportunities, empowerment, and inclusion. The overarching vision is that "New Zealand is a non-disabling society—a place where disabled people have equal opportunity to achieve their goals and aspirations, and all of New Zealand works together to make this happen" [16] (p. 6). The strategy has eight target outcomes focusing on education; employment and economic security; health and well-being; rights protection and justice; accessibility; attitudes, choice, and control; and leadership. The New Zealand tourism sector certainly needs to be involved in contributing to these strategy outcomes and working to address how they meet the expectations of their access consumers.

\section{Accessibility—Moving Beyond Barriers to Accessible Tourism Experiences}

Scholars argue that the tourism industry has not adequately considered the concept of accessibility, nor are they making changes to their current operations to better cater to those with disabilities [4,17-20]. It has been surmised that the tourism industry is generally unaware of the population of disabled people or the fact that their facilities or services are not accessible to everyone [18] and has ignored this valuable market [9]. As such, the tourism literature is replete with studies of the inaccessibility and barriers to participation in tourism for travelers with disabilities [19-21]. The barriers to participation are generally categorized as physical, informational, and attitudinal [22]. Yet, participation in tourism is found to contribute meaning and to an individual's quality of life [20,23-26].

Increasing the level of a person with disabilities' quality of life depends on the inclusiveness of society and the community in which they live. People with access requirements tend to be segregated and ignored within society [26-28] and face social stigma [9,10,26]. People with disabilities are not offered the same opportunities as those who are able bodied, and their voices are being disregarded from communities [27-32]. However, Darcy and Dickson [3] have argued it is time for society to change its attitude and behavior towards people with disabilities and welcome them into communities and provoke interaction and participation. People with access requirements, like able-bodied people, want to meet new friends, have opportunities for social interaction, and be included and participate in a recreation activity to enhance their lives $[20,23]$.

The concept of accessible tourism, or barrier-free tourism, focuses on providing independence, equality, and dignity for travelers with disabilities or those requiring access needs through the delivery of universally designed products, services, and environments [2]. The purpose of accessible tourism refers to tourism providers being able to cater to the needs of a range of consumers with access needs, including persons with disabilities [22]. The implementation of accessible tourism in businesses requires the removal of institutional and environmental barriers in society, and encompasses accessibility in the physical environment, in transportation, and other facilities and services [29,30]. Accessible tourism can only effectively operate when stakeholders within the organization, and within the wider tourism system, collaborate to enable people with access requirements to travel, ensuring that the whole journey to, from, and within the destination is accessible, along with their experiences [10]. A number of best practice models have been considered within the tourism literature [30,31].

The most common restriction for people with access requirements is structural and architectural barriers that limit a person's accessibility [19]. The design of facilities is crucial for a person with access 
needs to ensure that they are able to achieve tasks without health and safety risks or difficulty while in the facilities. Sometimes businesses make certain areas accessible, but the route or the accessibility chain breaks when other crucial areas are inaccessible when needed to be used [30,31]. For example, when hotels design accessible rooms to be on the second floor, but do not think to install elevators to help with the ease of access to those rooms, it poses challenges for the traveler [17].

In the tourism value chain, effective and efficient transport systems are crucial for people with access requirements but are seen as one of the most difficult barriers they encounter in travel and tourism $[17,20]$, primarily because the services offered are either difficult to access, not reliable, or do not meet the needs of the individuals [32,33]. The lack of accessible public transport excludes those who have access requirements, as the current transportation methods are designed to cater for people with able bodies [32,34]. Research indicates that people with access needs only make one third of the number of trips per week as those without disabilities [32]. As such, people with access requirements decide between staying at home or waiting for family or friends to provide transport to achieve tasks or activities [35]. If transportation providers want to avoid this occurrence, they need to consider the entire trip "from door to door" for people with access requirements [35] (p. 3). Taxi companies are known for offering accessible vehicles for people with access needs. However, people with access requirements are reluctant to use their services, as they are unreliable and costly [36]. Transport that is offered to people with access needs is viewed as a "special service" and segregates those who use those particular services [37]. People with access requirements are dependent on those specialized services, because there are limited alternatives for them to reach their desired destination.

Given the above, for transport to be fully accessible, transportation agencies need to understand the nature of travel demand and the reasons for travel and specific needs [37,38]. For instance, transportation organizations need to consider implementing education and training around how to interact with people with access needs. Most importantly, they need to understand that flexibility is key for people with access requirements, because they are heavily reliant on public transport. Therefore, transportation agencies need to include people with access requirements involved with the decision making process and planning to ensure their requirements are being meet whist travelling [36]. Improved mobility for people with access requirements enhances the quality of life through extending accessibility to both facilities and opportunities, and alleviates social exclusion [32].

In addition to transport providers, travel agents too pose barriers to tourism for people with disabilities. Specifically, the lack of training for tourism employees explains why travel agents are criticized, because they are seen as gatekeepers of travel information [8]. They lack knowledge in access needs for tourists and become an obstacle providing accurate information. There are three reasons to why travel agents are criticized: they lack the understanding of market needs from people with disabilities, information provision, and their willingness to cater for the sector [17]. When travel agents are recommending destinations of travel, they do not consider accessibility and whether it would be easy to get around and have suitable facilities that meet their needs. This is primarily because they are not aware of the difficulties that people with access needs have when travelling. There have been instances where travel agents have indicated to access needs people that certain destinations are accessible, but upon arriving to the destination, the client realized that the agent had a different understanding of "accessible" [21].

It is therefore argued that effective tourism providers need to be educated and trained to recognize the different needs of those who have access requirements [38]. They should be able to identify the barriers that restrict those individuals and be able to utilize that knowledge to develop strategies to allow people with access needs to participate. If tourism providers want to definitely understand the needs of people with access needs, they need to first determine how those individuals in that group identify themselves, what their travel preferences are, and what form of communication channel is best [19]. When tourism providers are able to cater to people with access needs, they will potentially obtain long-term customers who are loyal to the businesses that were able to best serve their needs [39]. 
Access tourism in New Zealand, the context of this study, is practically ignored and not acknowledged $[10,18]$. It is obvious that New Zealand has not realized the potential in having accessible environment, information, products, and services to better cater for people with access needs. Yet, research has shown that once the tourism sector is educated properly to understand the challenges and barriers they begin to understand and potentially influence a change of attitude and behavior [40]. As such, tourism industry operators and employees need to be equipped with the relevant information and skills necessary to recognize people with disabilities as a very important market segment, and there are opportunities to make progress towards making tourism more accessible. However, making tourism accessible requires greater consideration of the challenges and barriers to be eliminated through the offering of tourism products and services that cater to the needs of people with access requirements and enabling expected and enjoyable experiences.

\section{Methodology and Research Design}

This study adopted a social constructivism framework, as this paradigm aligns with the social model of disability that seeks to understand individuals within their broader social context $[13,14,27,41-43]$. In doing so, we reject positivistic research approaches for a number of reasons, but namely because they apply a deductive approach that does not privilege the participant's lived experiences $[43,44]$. Critiques from disability researchers have identified that this paradigm tends to be used by abled bodied researchers who do not understand both the dehumanizing historical context of this perspective nor grasp the lived experience of living in a society that disables, labels, and restricts the disabled body [42,44]. The positivist paradigm also neglects agency and uneven relationships of power between the research academic and participant, all of which replicates the lack of agency in the access person's everyday experiences [10,45-47].

In contrast, the social constructionism paradigm examines the language, discourses, institutions, organizations, and systems that shape a person's world-view to understand the subjective experiences of the participant [42-44]. For those working in this paradigm, there is no ultimate truth, foundations, or correct way of conceiving the world, rather it is an interpretation shaped by individual and broader influencers on the phenomena [42-44]. This paradigm rejects the medical model of disability that relies on positivism's generalizations and reductionism, instead it draws on its roots from phenomenology to examine "self-evident, taken-for-granted truth[s]" [42] (p. 24). Assumptions, everyday myths, and practices that are seen as common sense become the focus of researchers working within this paradigm.

Critical scholars who have adopted this framework also examine the concept of "agency" to investigate issues of power, assumptions, and structures that can facilitate or create exclusion [40,42,44]. Aligning with the social constructivism paradigm, the perspective employed in this study was the social model of disability [14]. In rejecting the traditional positivist medical model of disability, we are against positioning people living with a disability, impairment, or access issue as passive and invisible in society and our research. The social model of disability endeavors to identify the central causes of broader systems, polices, negative attitudes, discourses, and exclusionary actions in society that are contributing factors to disabling people $[14,15]$. The fundamental aspect of social model of disability is "equality", social change that empowers and enables people to make decisions about their lives. The social model of disability tends to focus on changes for society that could be implemented around, for instance, attitudes and labeling, and aims to ensure that systems and environments are inclusive $[13,14,41,42]$. For this model then, disability arises because of language, discourses, systems, environment, and discriminatory policies that people with access requirements face.

In this study, qualitative semi-structured interviews, both in-person and online, were adopted to enable participants to voice their expectations and experiences of travel and tourism in New Zealand. These tools were adopted to ensure that we facilitated the inclusion of participants who may have not been able to attend a face-to-face interview. As Table 1 illustrates, all our participants had a physical impairment and none had any cognitive difficulties. The semi-structured interviews began with 
open "ice-breaker" type questions asking the participant to share their background and defining and describing expectations regarding their ideal New Zealand travel and tourism experience. The purpose of this questioning was to get the participants focused on the topic and start thinking about their travel and tourism experiences. These were followed with more open-ended questions around planning, transport, accommodation, defining accessibility, and tourist experience/events. These questions asked participants to comment on their New Zealand experiences, what they thought worked well, and what they considered could be implemented to create more enjoyable experiences for the access tourist. The final question asked the participants to describe their ideal experience and what key points they would like to pass on to organizations who need help to move towards accessibility.

Table 1. Participants who volunteered for the study.

\begin{tabular}{ccc}
\hline & \multicolumn{2}{c}{ In Person Interview Participants: 11 Interviewees } \\
\hline Interviewee 1 & Male: Age 31-40 & Wheelchair user \\
Interviewee 2 & Female: Age 41-50 & Sight impairment \\
Interviewee 3 & Male: Age 20-30 & Wheelchair User \\
Interviewee 4 & Female: Age 51-60 & Sight Impairment \\
Interviewee 5 & Female: Age 31-40 & Hearing and Sight Impairment \\
Interviewee 6 & Female: Age 41-50 & Sight Impairment \\
Interviewee 7 & Female: Age 20-30 & Sight Impairment \\
Interviewee 8 & Female: Age 31-40 & Sight Impairment \\
Interviewee 9 & Male: Age 31-40 & Slight and Hearing Impairment \\
Interviewee 10 & Male: Age 31-40 & Sight Impairment and Support Access Organization Employee \\
Interviewee 11 & Female: Age 20-30 & Wheelchair user \\
\hline & Online Interview Participants 16 Interviews: 10 Fully Completed \\
\hline Participant 1 & Female: Aged 20-30 & Wheelchair user \\
Participant 2 & Male: Aged 31-40 & Sight Impairment \\
Participant 3 & Female: Aged 31-40 & Wheelchair user \\
Participant 4 & Female: Aged 31-40 & Sight impairment \\
Participant 5 & Female: Aged 20-30 & Slight Impairment \\
Participant 6 & Male: Aged 41-50 & Wheelchair user \\
Participant 7 & Female: Aged 31-40 & Wheelchair user \\
Participant 8 & Female: Aged 31-40 & Sight Impairment \\
Participant 9 & Male: Aged 31-40 & Sight impairment \\
Participant 10 & Male: Aged 31-40 & Sight Impairment \\
\hline
\end{tabular}

Purposeful sampling criteria was adopted in this study, as illustrated in Table 1, to select participants who were information- and experience-rich, aiming to develop in-depth insights into their tourism experiences [43]. The interview participants included any individual who had an impairment, disability, long-term health issue or physical access requirement and who had recently experienced domestic travel in the last six months. In total for this study, the interviews included twenty one people who had participated. The interview questions were first pilot tested with participants from an access organization to reduce any misunderstandings before being conducted with the twenty one participants.

A call for participants was placed in various social media channels and on community access organizations' noticeboards. Eleven people volunteered to be interviewed for the in person interview. To ensure anonymity for the participants, numbers are used to disguise interview participants' identities. All participants received ethical information as per our agreement with the University's ethical committee. The benefits of conducting in person interviews are that this tool is appropriate for the paradigm and provides flexibility for hearing richer in-depth information from participants. In person interviews are suitable, as they enabled opportunities for follow up or impromptu questions from both the researcher and participants, as well as allowing participants to clarify their comments and elaborate when required on their answers. This tool was essential for both able bodied researchers and also the tourism sector to adopt, as it allowed deeper understandings to emerge of accessible experiences and undermined many of the stereotypes prevalent in the sector about accessibility.

The online interview asked the same basic demographic questions as the face-to-face interview, followed by the same open-ended questions as the semi-structured interviews. The aim of the interview conducted online was to allow people to participate who may not have been physically 
able or well enough to be involved in the face-to-face interviews. The online option offered a second communication channel for participants to share their experiences with us about domestic tourism and travel. Access to the online interview was communicated to potential participants by access coordinators and employment consultants from three community service organizations. In total, there were 16 online interviews, with ten fully completed interview documents returned to the researchers. Six of the online interviews were incomplete and discounted from our analysis. In total, the study had 21 participants who shared their experiences about tourism and travelling in New Zealand.

Thematic analysis was used to analyze both sets of data and is the most common form of analysis in qualitative research [43-47]. One of the advantages of thematic analysis is that it is theoretically flexible, allows the researcher to focus on meanings across data sets, and focuses on what is common across participant experiences [43-47]. The interviews were recorded and transcribed manually. The completed online interview information was collected and included with the interview data analysis. The analysis procedures followed the inductive thematic analysis approach used by previous qualitative scholars $[46,47]$. The first step is to get a sense of the whole data through reading the transcripts text while considering our purpose in the study. This is the text and first literal coding stage of analysis. Charmaz [46] advises that as researchers analyze, they should be asking themselves "what is going on? What are people doing? What do these actions/statements take for granted? How do structure and context serve to support, maintain, impede or change these actions and statements?". The next step is to identify patterns, themes, and convergence. This is the second step that focuses on the analytical aspects of analysis. In this second step, the researcher is trying to identify what is important for the participant, what is common, and importantly what is less apparent and or missing or not mentioned. The final step is the focused coding of themes and elucidate meanings with a synthesis of the relevant literature and theories. A key advantage of this three step process of thematic analysis is that it is theoretically flexible, allows re-reading, the researcher can focus on meanings across data sets, and it identifies what is common as well as invisible across participant experiences [43-47]. Ethical approval for the study was gained from the University of Waikato's ethics committee. If also asked, ethical discussions were held with various access organizations and communities. This was to build trust and ensure that we were informed by any ethical advice and requirements required by the access sector and communities.

\section{Results and Discussion}

Our results illustrated that for all twenty one participants, accessibility is a diverse experience requiring different, creative, but inclusive understandings and solutions. Yet, in noting this diversity of experience, it was clear from our results, as identified by McKercher and Darcy [19], "that people only become 'disabled' when faced" (p. 62) with structural, societal discourses; inadequate information; and interpersonal naiveties encountered from others in the industry [20]. Our results certainly illustrated these issues for the access tourist, and if addressed, then this would enhance and perhaps even exceed the expectations of this growing segment. Participants identified that developing inclusive understandings can also sometimes provide inexpensive solutions for change that could be easily implemented in the New Zealand domestic tourism sector. For many of our participants, there was a clear overwhelming desire for the sector to first become more informed about the access consumer.

The themes illustrating these commonalities were grouped as defining and gaining accessibility, information gathering and planning, transport, and education. All participants were passionate about the need for accessible tourism in New Zealand. Participants also lamented that despite having a New Zealand Disability Strategy, there were still no clear regulations around accessibility. In effect, the strategy is a suggestion for New Zealand tourist organizations, rather than a policy regulation. Although international travel and tourist sites had their challenges for all the participants, they stated that their home country of New Zealand was particularly poor in meeting their expectations in an equitable and inclusive manner. Domestic tourism restricted participants from leading independent and dignified lives in their own country. The following section will illustrate and discuss our participants' expectations and experiences of tourism. 


\section{Defining and Gaining Accessibility}

Accessible tourism has been defined by scholars as activities in tourism that people can freely choose to participate in and enjoy regardless of any impairment, functioning abilities, or physiological imperatives [3]. In this study, participants were asked to define and describe their understandings of accessible tourism to gain an insight into their expectations and what their ideal tourism experience would involve. It was clear from their description of accessibility and what was required to gain access that at times the needs of each disability did differ. This was not an unexpected finding, as working within access communities, we were well aware that an accommodation for one type of access may create a barrier for another. For instance, lighting or floor coverings could assist those with a visual impairment, but cause problems for wheelchair users or those with seizure disorders [48]. A study focusing on the design of a building for access organizations in the USA found that in grassroots consultation with users, solutions were identified to these kind of issues, so that the building could be used by a wide variety of access users [48]. This heterogeneous aspect of disability did not pose issues for defining access or identifying solutions to gain accessibility, as the process of hearing and including diverse stakeholders was crucial to the success of the building process.

Despite individual differences depending on their personal situation, there were commonalities regarding defining what access means that were stated by all participants. For instance, interviewee 2 said "tourism is for everybody, so it should be equal whether you are impaired or not and should be accessible", while online interview participant 9 wrote "it's about equity of access". Other common words used from the data to define the term were "equity", "opportunities", "everybody", "normal", "same", "independence", and "equality". All these words illustrate their desire for inclusion, participation, and being able to gain the same tourism enjoyment as others. As Darcy and Dickson [3] have argued, tourism should include planning for achieving independence, equity, and importantly dignity. Dignity, as Hobson [49] states, "is essential for a life well lived ... worth living" (p. 22), and for Bolton [50], it entails "respecting people as people ... importance of human relationships ... offer autonomy" (p. 9). These terms from our participants encompass much of Hobson and Bolton's $[49,50]$ sentiments around accessibility being worthy of being included, respect, and having a choice to be involved.

Gaining choice and control was seen as essential and desirable by all our participants in order to achieve dignity and independence. Interestingly, many participants felt that the local tourism destinations and sector was much more difficult and less likely to be inclusive compared to overseas travel and tourism organizations. Frustratingly, their desire for access and inclusion was rarely met with notable award-winning local examples, mentioned by several participants as not being accessible. This restricted their inclusion and reduced their participation with their local tourism activities. Participants said they needed to rely on others, ask for help in order to explore the tourism activity, and they felt that they "become a burden". Another person commented that they "cannot travel in New Zealand like I do overseas". Participants noted that there were certain "no go zones" (interview participant five) in their local areas. These areas, for instance, included locations that were physically difficult to navigate around, into, and through due to steepness, gravel, and small pathways or bridges. At the time of the study, participants that were visually or sensory impaired needed to plan their visit, as access to volunteers was limited and there were reduced accessible signposts to provide information or maps and no access to accessible devices such as earphones. Unfortunately, many accessible tourists found they could not enjoy their local tourism activities or venues and had to adapt themselves to the environment, which reduced their expectations and overall enjoyment of the activity.

This finding illustrates how society excludes and reinforces dependency. Planning their local travel and tourism become an essential, but for some of our participants, this was a dreaded process they had to endure. A solution offered by some of our participants was that they or an access advocacy organization could offer deeper understandings of the expectations of the access consumer to the sector if they were regularly included in participatory dialogues and opportunities for planning. Tippet and 
Fraser How [51], for instance, have argued that co-participatory dialogue tools and engagement practices can help to "structure effective thinking ... how dialogue can reframe issues" for planners to aid deeper insight into access issues (p. 128). Their work illustrates through various case studies how planners and business stakeholders have gained tacit understandings through collaborative dialogue and planning that "surface[ed] ... place-based knowledge ... [for] building relationships of trust and mutual understanding [and] capacity building to support further action and learning" (p. 128).

\section{Information Gathering and Planning}

Accurate, quality, and honest information is essential for accessible tourists. Prior planning for people with access needs becomes essential as they try to determine if they can get into the tourist venue and prepare for any possible occurrences on trip [38]. Similarly, previous tourism scholars have noted that planning and accurate, honest information are essential for tourism customers [30,38,39]. Accessible tourists need to ensure they have prepared and packed any required equipment that may be needed for the trip. They sometimes may bring specific accessible equipment or resources to assist their visit. Having clear, detailed, and easily accessible information communicating the accessibility of the venue greatly assists the planning of the access consumer. Availability of clear, accurate communications ensures access consumers can enjoy their trip, activity, or venue.

Transparent information on an organization's communication channels provides a relatively inexpensive change for the sector to implement. During the planning process the access consumer extensively researches, considers, and plans their tourist trip with as much information about the tourist venue as they can source. They are seeking to identify how accessible the accommodation, transport, and activities are at the venue and if it would be suitable for their needs [52]. In addition to knowing what is available, the access consumer also needs to be able to identify what is not at the venue so they can prepare any equipment that they may need. Therefore, the availability of clear information that is communicated via a variety of channels and especially online information is an essential information resource for the access consumer. These types of communications can provide accurate information for a person with access needs to make informed decisions about what to expect at their travel destinations and to ensure they experience a pleasurable trip [30].

All our participants mentioned the extensive information and research search they conduct before deciding to go on a local tourist trip. For example, interview participant 4 said that in order for her to have a relaxing and stress free experience, she need to have conducted extensive pre-planning before the trip. She mentioned how she would begin researching a trip a year in advance so that it would give her enough time to collect, contact, and research information. Previous scholars have also noted in their research that access consumers will conduct extensive research to reduce uncertainties and ensure they are prepared for the trip $[17,21,22]$. Information searches become essential for planning around what the tourist venue has to offer the access consumer and also identify what the access consumer needs to pack to enjoy the trip. Many of our participants had huge folders compiled with information that they had gathered before booking or planning any trip. Previous studies have also indicated that clear, accurate information is essential for the access consumer to gain an expectation of what is at the venue and importantly, what they need to bring along to ensure they can be included $[12,17,19,26,27]$.

Every access individual has different needs, which would reflect the type of information required. To be clear here, however, the sector is not expected to provide a diverse range of equipment for all accessible needs. Instead, if they can clearly communicate what they can provide at the venue and what is not available, then the consumer can supplement with their own resources. Unfortunately, this is not always the case, as interviewee participant 7 stated that a local tourist destination, for example, does not have a lot of information about the level of accessibility for getting around the venue. This, the interviewee noted, made it difficult to determine whether the venue was safe and what to prepare for when packing for the trip.

A relatively inexpensive solution for the sector is to develop clearer information on their communication channels. In order to understand what type of expectations the access consumer 
would seek, communications dialogues with local stakeholders could help to develop the sector's understandings. This could be achieved by collaborating and developing regular networks and planning sessions with local access organizations. The access organizations could then inform and develop the tourist sector's understandings of what to include in their communication and what to clearly state that they do not provide. For instance, some might require information in relation to where there would be grass for their guide dog to walk around or if the accommodation offers room service. If this information was not communicated, then, as one of our participants describes it, it is a case of "potluck" (interview participant 6) and hoping for the best. In situations where people could not access information, then they would decide not to attend. This conclusion that our participants stated reflects similar findings in the accessibility tourism literature too [17,19-21].

Developing trustworthy relationships with travel agents was identified as crucial for our participants. Interview participant 5 mentioned that the local access organization has a travel center that they use to book trips. They felt they could trust and be confident that this blind and low vision advocacy organization had screened particular providers. For instance, the travel centers that were endorsed by the access organization are provided with training and key questions to ask providers in order to assess the tourist providers suitability. These questions ranged from: was it accessible? Did they orientate access consumers on arrival to the accommodation? Did they have accessible online services? Many of these questions able bodied people would probably take for granted but are essential for the access tourist. Interview participant 7 said that people need to know how to ask the right questions in order to get the information that is most useful to you. However, rather than people with access requirements having to learn to ask the right questions or rely on others to find the information; tourism organizations and their websites could be easily be equipped to answer all those questions through the click of a button.

There were several of our participants that said they preferred to use travel agents to help book trips overseas. They stated that travel agents tend to have extensive networks to tourist providers and are quicker at finding information for the access consumer. Interview participant 3 said that familiarizing yourself with a travel agent in order to form a trusting relationship was beneficial for both parties. The agent could gain a richer and more in-depth understanding of the access consumer expectations, and the information search workload for the access consumer was reduced. This extra training ensured that the travel agent was trusted to ask the appropriate access questions and make bookings appropriate for the person's access needs [17]. All of our participants mentioned that once they found a travel agent or tourism provider that met their expectations, they become loyal to that business.

The problem with booking through a travel agent, however, was that they too rely on information provided by tourism organizations. As mentioned previously, this information may be limited or not consider the diversity of access consumers. For example, online interview participants 4 and 5 similarly noted instances where a hotel might say that it is accessible, but when reaching the destination, participants realized it is only accessible for wheelchair users and not for people with sight impairments. If that organization met the needs of the person, many of our access participants in the study stated they would frequently visit and become loyal to venue or accommodation provider. Participants commented that loyalty developed because they developed a relationship with this organization who had gained an understanding of their expectations and kept information about their needs on the organization's database.

Information online was identified in our participants' experience as often too vague or general regarding how the accessibility of the venue or assumptions were made that accessibility related only to wheelchair users. Participant one in the interview stated that they would never consider venturing off and would only go to places that are familiar and accessible. This restricts the number of places that people with access requirements can visit. Every trip or move needs to be pre-planned so that they are able to ensure a positive experience and have a good peace of mind knowing that they are prepared [30,31]. Interviewee participant 3 stated that people with access requirements have this 
"hopeful desire and expectation of being able to turn up anywhere to participate in tourism just like a normal person". As many of our participants lamented, unfortunately, this is not always the case in New Zealand.

All participants stated that they needed to spend an inordinate amount of time researching the destination they plan to visit to avoid any factors that might potentially ruin the experience. It is crucial for people with access requirements that information is clear, accurate, and states what is there and not provided. Too often, the information assumes that disability only relates to wheelchair users. People with access requirements wish to have "all the information and let us make the decision" to gain independence, as participant 6 stated in their interview, but far too often, decisions are made for them rather than with them or by them. Collaborating with local access organizations was suggested as an inexpensive solution for the tourist sector. This collaborating would develop a broader awareness for the sector of the access consumers' needs and expectations. The benefits gained from this collaboration are that tourism experiences meet the basic requirements and could even exceed these needs to become enjoyable, resulting in loyalty from the access consumer to that tourism provider.

\section{Transport}

Previous researchers have argued that access to regular, reliable, and frequent public transport is essential "to support their community participation and help migrate the impact of disability on their lives" [53] (p. 233). Regular public transport can also have wider additional benefits for environmental sustainability, as it tends to reduce a reliance on private cars [32,37]. The rural nature of New Zealand, even in the more urban areas, shaped our access participants opportunities to travel and become a tourist in their own country. For example, there was significant criticism from all our participants that focused on the lack of frequent and on time buses. Lack of flexibility in transport was the greatest barrier and frustration that our participants identified to their full inclusion in tourism activities and destinations [51]. All participants had strong opinions on how transportation should be improved based on their experiences of using the services. Public transport for people with access is vital, as for most people it is the only mode of transportation they have to get around. For example, interviewee participant 5 mentioned that it was difficult for her to visit a local venue that was not too far from her home due to the lack of direct transport to that tourist venue. Instead, the access tourist would be required to catch several buses before they reached tourist venue, and most of those buses were infrequent.

Previous scholars researching accessibility in transport and planning have noted that it is crucial to consider in any design the expectations of consumers with restricted and access issues $[12,54]$. Consumers with access needs should be able to reach and get involved in activities, especially in their local areas. Within planning for transport, the three issues of sustainability, access, and safety are important and should be the focus for any transport design. Much of this literature has called upon planners to work with and hear the expectations of access consumers, especially as there is a diversity of expectations depending on the person's need [18,31,32]. Critically to note in the literature, sometimes obtaining social inclusive in sustainability may create tensions with environmental goals for sustainability [48,54-57]. For instance, adding an extra lift can increase demand on electricity [50]. Widening public transport access, however, did meet both environmental and social sustainability outcomes.

Tyler's [54] UK study of transport and access to the museums on Exhibition Road, for instance, noted that "there was a definite difference between the responses of visually-impaired people and mobility-impaired people" and concluded that "that some people are not going to Exhibition Road because they feel uncomfortable [rather] the museums are no longer reachable and their ability to enjoy them depleted" (p. 64). Similarly, in our New Zealand study, many participants wanted to visit a local beach, which was about $45 \mathrm{~min}$ away by car, but access for those without private transport was difficult. Participant two stated in her interview that the buses to this local beach do not run on the weekend. She would have to try to visit during the work week, and there are only four buses a day 
with the last one leaving to return to the city around 4 p.m. Lack of direct and frequent transport reduced independence, inclusion, and freedom for the access consumer to enjoy tourism activities.

An alternative mode of transport participants mentioned using were taxis. A benefit for some access tourists was that they only paid half the price fares. The other benefit was that if you were a regular user, as interview participant 10 stated in his interview, the firms had key information about access customers' requirements, so they could make their staff aware of the person's needs. Again, the participants faced restrictions, as only two taxis could accommodate physical access requirements. If a full paying customer called, they frequently got priority over the access customer. On weekends, there is a significantly reduced number of taxis operating, as interviewee 10 commented that he was told there were only three taxis on Sundays. Three online interview participants suggested that building relationships with taxi drivers that provided positive, supportive experiences and asking for their business card is the best method to secure their custom. Despite building these relationships and sharing information about their needs, people still occasionally encountered drivers that did not understand or accommodate their requirements. Transport enables tourists to visit and get to point $\mathrm{A}$ to point B; without accessible transport, people will choose to only go to places that are within walking distance or places that are most convenient to their homes [35].

\section{Education}

Education and training that creates awareness and opportunities for providers to meet people with different access needs is essential. As McKercher and Darcy [19] argue, while educational training workshops can reduce negative stereotypes, it is the interpersonal contact and opportunities to meet that are "more prevalent and longer lasting" (p. 62). Interview participant 10 suggested that it is important for tourism students to be exposed and made to consider accessibility. Interview participants 7 and 10 both mentioned that more tourism organizations needed to invite people with access requirements to provide feedback, share their experiences, and contribute to helping organizations to orientate their mindsets towards accessible services. As interview participant 3 stated, "one wheelchair user cannot be a representation of all wheelchair users", as a homogenized approach does not assist the access tourist's expectations or gaining an enjoyable tourism experience. For example, interview participant 5 experienced a negative and homogenized approach to service approach when they boarded with Singapore Airlines. There was an assumption that all disabled people could not do anything, as the participant noted Singapore Airlines "MUST look after us"; it was a "this is our training and this is how we implement it" inflexible 'one-size-fits-all' approach. The participant overheard one of the air stewards say to one another "if you don't make them sit down we will get in trouble". The airlines treated everyone the same, reducing autonomy, and the participant stated that the airline assist system felt as though they were being "babied and treated as children".

Interestingly, interviewee 8 worked for a corporate fuel company based at one of their petrol stations. She said that the company as part of its social sustainability commitment integrated accessibility and inclusion in their training as well as daily performances reminders. The company has education and frequent workshops that train their employees in accessibility customer service skills. For instance, interviewee 10 commented that they have an inclusive hiring policy, so there are many opportunities for employees to mingle with accessible colleagues. She also mentioned that the organization helps their employees recognize, modify their language, and identify interpersonal communication techniques to enhance their customer service for a person that may have an access impairment. In their training, for example, she noted that "[the petrol company's] state that [their] employees should simply ask 'how would you like to be addressed?' ... told not to lean on someone's wheelchair or talk to the caregiver instead they need to address the person". Similar and inexpensive solutions such as these could be easily added into the etiquette customer service training in the tourism industries. It is the little things that people do that can make people with access requirements feel valued, included, and independent within the tourism activity and destination. 
Creating awareness through educating the tourism sector was considered crucial by our participants and in the literature, as it removed the responsibility, guilt, and stress away from the access tourist [51-57]. For instance, interview participant 2 wrote that they would not visit a local venue if there was no companion available, as they would feel a "burden and stress out". They recommended a solution for local New Zealand venues based on their previous international tourist experiences. Interview participant 2 also stated that the local venue could offer audio headsets that provided an audio description of their destination alongside the guided tours provided. They had experienced a similar service offered during an international tourist experience in the United Kingdom. It was these services that allowed the participant with sight impairments to feel as though they were treated as equals and not a burden for others. It is with education and opportunities to interact that changes in perception will occur for the tourism industry [39]. Due to the current lack of tourism industry awareness and education and particularly assumptions that access was only related to wheelchair users, the tourism sector has made the access consumer invisible and excluded.

\section{Conclusions, Practical Implications, Limitations, and Further Research}

The originality of this study was that New Zealand tourism, despite being in a first world country, still does not consider the access market [27]. In addition, the New Zealand Disability Strategy is a recommendation that can be easily ignored, or businesses can adhere to the bare minimum. Assumptions in the sector still prevail around access tourists as not being interested in travelling or not having the financial means to engage in tourism. As the statistics illustrate, both in New Zealand and internationally, this is a financially viable market, especially when facing Covid-19 border restrictions for international tourists. In contrast, our participants illustrated that they were certainly willing to overcome any restraints to engage in local tourism activities. The participants also highlighted that if the organization meets their needs and even exceeds their expectations, then the access tourist becomes a loyal and frequent customer. In order to meet and exceed the access consumers' needs, the tourist sector needs to engage with their community stakeholders more closely and in an authentic manner that develops reciprocal relationships. For instance, as well as holding collaborative discussions with access organizations, the sector could reconsider their hiring policy to open up to diverse employees with lived access experiences. Both of these solutions would communicate dignity and sharing knowledge between the community stakeholders and the New Zealand tourist sector.

This explorative research indicated four key themes from the data, namely, defining and gaining accessibility, information planning and gathering, transport, and education. The participants also identified inexpensive solutions that were not currently implemented and are practical in order to begin the change towards obtaining accessibility in New Zealand tourism. As mentioned previously, for the sector to meet the recommendations of the New Zealand disability strategy, it needs to work with diverse stakeholders in planning and evaluation strategies. This would allow space to share knowledge, hear experiences, and identify the expectations of access consumers. These actions would open up the sector to the access market and, importantly, support tourist activities that maintain a sense of dignity, where access tourists are not treated as "broken" individuals that need to be cared for 24/7. Reorienting to become inclusive, listening and focusing on developing relationships that create authentic communicative dialogue with stakeholders is crucial. This orientation also avoids stereotyping the access tourist with language, policies, structures, and practices, all of which reduce autonomy and independence [10]. Being inclusive targets both social sustainability and opens up the profitability of the sector, particularly when faced with the current closure of international borders in the COVID-19 climate.

Suggested improvements for implementation from our study participants stated that having information that is readily accessible, honest and available in many different channels and formats was essential. This would enable access consumers to effectively plan their trips, make all tourists' lives much less stressful, reduce social barriers to inclusion, and add to their quality of life. This would also mean that the tourism sector is starting to address and meet the New Zealand Disability strategy's 
outcomes. Most people find the planning process very difficult, because they are unable to acquire the information they need to be able to make good judgment of whether it would be feasible and accessible for them to attempt to travel to the destination or use that tourism service. This current lack of effective and clear information reduces the regularity of people travelling. Instead, access consumers tend to travel or visit places that they are already familiar with and know are accessible.

An overarching problem from the participants' perspective restricting their inclusion in New Zealand tourism was inaccessible transport and a neglect in the education of the tourism industry around access consumers. To address this issue, our participants called for a greater need for diverse stakeholder inclusion and voices to be heard within both the transport planning processes and in the education of tourism professionals. Tourism organizations are still working with myths and assumptions all of which neglect this increasing financial market. There is a lack of education and understanding from the tourism industry in identifying the needs and expectations of people with access requirements. Therefore, developing an understanding of the communication, interpersonal, assisted technologies, and customer skills that can be easily acquired to become inclusive to the access consumer is needed. Indeed, our participants noted that many in the tourism sector do not ask the "right questions". A solution for implementation here is to involve people with diverse access requirements in developing education and training workshops, which would be a fundamental crucial step for change within the sector, While also re-evaluating the hiring procedures of tourism organizations, as these could be easily changed, to open up to include and encourage applications from diverse employees who have a richer understanding and tacit knowledge of access requirements to bring in to the sector.

Regarding limitations and further research that could be developed from the study, a focus on certain New Zealand tourist destinations and perhaps using traditional statistical methods to quantify the sector would be helpful now that this explorative study has been completed. In addition, an action research approach could be used to determine how the New Zealand Disability Strategy could gain more "force" to be implemented in a manner that creates accessibility and inclusion. The disability strategy is currently advisory, not mandatory, and many of our participants lamented that tourist organizations were simply ignoring this sector or considering these communities as too difficult to meet. Access participants and organizations have a wealth of tacit, lived knowledge and expertise that is currently not connected with the tourism sector. This is a pity, as collaborative stakeholder projects and discussion offer potential for change that would enhance the tourist's sector's offerings and benefits. Future research could develop stakeholder discussion "think tank" conversations across a range of community groups who rarely interact with each other. This would ensure that the industry did not dominate the conversations and that tourists with access needs are actually heard and involved in planning for accessible inclusive change [10,20,31].

In conclusion, this study has called for more inclusive social sustainable strategies and practices to enable access New Zealand stakeholders to participate in domestic tourism. Involving access consumers with bottom-up grassroots processes is crucial for the tourism industry, as it needs to hear the tacit experiences and expectations of the access consumer in order to make changes for the sector. The sector is neglecting the social and economic benefits of accessible tourism; something that has become even more crucial as international borders are closed and global tourists are restricted due to Covid-19. In addition to providing financial gains these solutions also offer the New Zealand tourism sector destination competitiveness within the domestic and international access market. Overall the benefits for both society and the sector are that sustainability values are actually practiced, enhancing access tourists' lives and businesses gain loyal, frequent customers.

Author Contributions: C.C.-W. Contributed to the conceptualization, background and dignity literature, study design, data collection, ethics application, analysis, community report, manuscript development, and writing. A.M. contributed to the conceptualization, accessibility tourism literature, study design, manuscript writing, and development. Both authors have read and agreed to the published version of the manuscript.

Funding: This research received no external funding. 
Acknowledgments: We would like to acknowledge our participants and the community access organizations that supported this project.

Conflicts of Interest: The authors declare no conflict of interest.

\section{References}

1. Porto, N.; Rucci, C.A.; Simon, D.; Garbero, N.; Almond, B. Critical elements in accessible tourism for destination competitiveness and comparison: Principal component analysis from Oceania and South America. Tour. Manag. 2019, 75, 169-185.

2. Luiza, S.M. Accessible tourism-the ignored opportunity. Ann. Fac. Econ. 2010, 1, 1154-1157.

3. Darcy, S.; Dickson, T.J. A whole-of-life approach to tourism: The case for accessible tourism experiences. J. Hosp. Tour. Manag. 2009, 16, 32-44. [CrossRef]

4. Ozturk, Y.; Yayli, A.; Yesiltas, M. Is the Turkish tourism industry ready for a disabled customer's market? The views of hotel and travel agency managers. Tour. Manag. 2008, 29, 382-389. [CrossRef]

5. Domínguez, T.; Fraiz, J.A.; Alén, E. Economic profitability of accessible tourism for the tourism sector in Spain. Tour. Econ. 2013, 19, 1385-1399. [CrossRef]

6. Disability Survey: 2013. Available online: https://www.stats.govt.nz/information-releases/disability-survey2013 (accessed on 4 November 2020).

7. United Nations World Tourism Organization. Available online: https://www.unwto.org/ (accessed on 4 November 2020).

8. McKercher, B.; Packer, T.; Yau, M.K.; Lam, P. Travel agents as facilitators or inhibitors of travel: Perceptions of people with disabilities. Tour. Manag. 2003, 24, 465-474. [CrossRef]

9. Gillovic, B.; McIntosh, A.; Darcy, S.; Cockburn-Wootten, C. Enabling the language of accessible tourism. J. Sustain. Tour. 2018, 26, 615-630. [CrossRef]

10. Cockburn-Wootten, C.; McIntosh, A.J.; Smith, K.; Jefferies, S. Communicating across tourism silos for inclusive sustainable partnerships. J. Sustain. Tour. 2018, 26, 1483-1498. [CrossRef]

11. Be Accessible. Join Mov. 2020. Available online: https://www.belab.co.nz/why-accessibility (accessed on 4 November 2020).

12. Darcy, S.; Cameron, B.; Pegg, S. Accessible tourism and sustainability: A discussion and case study. J. Sustain. Tour. 2010, 18, 515-537. [CrossRef]

13. Burr, V. An Introduction to Social Constructionism; Routledge: New York, NY, USA, 1995.

14. Oliver, M. Defining impairment and disability. Disabil. Equal. Law 2017, 3, 3-18.

15. Daiziel, H. The New Zealand Disability Strategy: Making a World Difference Whakanui Oranga; New Zealand Ministry of Health: Wellington, New Zealand, 2001; pp. 1-40.

16. Ministry of Social Development 2016-2026 New Zealand Disability Strategy. Available online: https: //www.msd.govt.nz/what-we-can-do/disability-services/index.html (accessed on 4 November 2020).

17. Packer, T.L.; Mckercher, B.; Yau, M.K. Understanding the complex interplay between tourism, disability and environmental contexts. Disabil. Rehabil. 2007, 29, 281-292. [CrossRef] [PubMed]

18. Access Tourism NZ. A Situation Report on the Current State of Access Tourism in New Zealand. 2015. Available online: http:/www.accesstourismnz.org.nz/2009/11/a-situation-report-on-the-current-state-ofaccess-tourism-in-new-zealand/\#more-99 (accessed on 4 November 2020).

19. McKercher, B.; Darcy, S. Re-conceptualising barriers to travel by people with disabilities. Tour. Manag. Perspect. 2018, 26, 59-66. [CrossRef]

20. Gillovic, B.; McIntosh, A. Accessibility and inclusive tourism development: Current state and future agenda. Sustainability 2020, 12, 9722. [CrossRef]

21. Buhalis, D.; Darcy, S. Accessible Tourism; Channel View Publications Bristol: Bristol, UK, 2010.

22. Felce, D. Defining and applying the concept of quality of life. J. Intellect. Disabil. Res. 1997, 41, $126-135$. [CrossRef]

23. Jenkins, R. Enhancing quality of life for people with learning disabilities. Learn. Disabil. Pract. 2002, 5, 29-35. [CrossRef]

24. Schalock, R. Three decades of quality of life. Focus Autism Dev. Disabil. 2000, 15, 116-127. [CrossRef] 
25. Australian Government Department of Social Services. SHUT OUT: The Experience of People with Disabilities and Their Families in Australia. 2014. Available online: https:/www.dss.gov.au/our-responsibilities/disability-andcarers/publications-articles/policy-research/shut-out-the-experience-of-people-with-disabilities-and-their-familiesin-australia?HTML (accessed on 4 November 2020).

26. McIntosh, A.J. The hidden side of travel: Epilepsy and tourism. Ann. Tour. Res. 2020, 81, 102856. [CrossRef]

27. Gillovic, B.; McIntosh, A. Stakeholder perspectives of the future of accessible tourism in New Zealand. J. Tour. Futures 2015, 1, 223-239. [CrossRef]

28. Smith, R.W.; Austin, D.R.; Kennedy, D.W.; Lee, Y.; Hutchison, P. Inclusive and Special Recreation: Opportunities for Persons with Disabilities, 5th ed.; McGraw Hill Higher Education: New York, NY, USA, 2005.

29. European Network for Accessible Tourism. What Is "Accessible Tourism"? 2013. Available online: http://www.accessibletourism.org/?i=enat.en.faq.744 (accessed on 23 November 2020).

30. Buhalis, D.; Darcy, S.; Ambrose, I. Best Practice in Accessible Tourism: Inclusion, Disability, Ageing Population and Tourism; Channel View Publications Bristol: Bristol, UK, 2012.

31. Darcy, S.; McKercher, B.; Schweinsberg, S. From tourism and disability to accessible tourism: A perspective article. Tour. Rev. 2020, 75, 140-144. [CrossRef]

32. Ahmad, M. Independent-mobility rights and the state of public transport accessibility for disabled people: Evidence from Southern Punjab in Pakistan. Adm. Soc. 2015, 47, 197-213. [CrossRef]

33. Soorenian, A. Disabled International Studentsin British Higher Education: Experiences and Expectations; Sense Publisher Rotterdam: Dordrecht, The Netherlands, 2013.

34. Austin, D.R.; Lee, Y. Inclusive and Special Recreation: Opportunities for Diverse Populations to Flourish, 6th ed.; Sagamore Publishing Urbana: Champaign, IL, USA, 2013.

35. Evans, J.; White, M. A Review of Transport Resources for People with Disabilities; ARRB Transport Research Victoria: Port Melbourne, Australia, 1998.

36. Armineh, S. Housing and transport: Access issues for disabled international students in British universities. Disabil. Soc. 2013, 28, 1118-1131.

37. Barrett, E.; Heycock, M.; Hick, D.; Judge, E. Issues in access for disabled people: The case of the Leeds Transportation Strategy. Policy Stud. 2003, 24, 227-242. [CrossRef]

38. Riley, C. Disability and Business: Best Practices and Strategies for Inclusion; University Press of New England Lebanon: Lebanon, PA, USA, 2006.

39. Bizjak, B.; Knezevic, M.; Cvetreznik, S. Attitude change towards guests with disabilities: Reflection from tourism students. Ann. Tour. Res. 2011, 38, 842-857. [CrossRef]

40. Garland-Thomson, R. Feminist disability studies. Signs J. Women Cult. Soc. 2005, 30, 1557-1587. [CrossRef]

41. Oliver, M.; Barnes, C. Disability studies, disabled people and the struggle for inclusion. Br. J. Sociol. Educ. 2010, 31, 547-560. [CrossRef]

42. Alvesson, M.; Skoldberg, K. (Post-)positivism, social constructionism, critical realism: Three reference points in the philosophy of science. In Reflexive Methodology: New Vistas for Qualitative Research; Sage Publications: Thousand Oaks, CA, USA, 2009; pp. 15-52.

43. Patton, M.Q. Qualitative Research E Evaluation Methods: Integrating Theory and Practice; Sage Publications: Thousand Oaks, CA, USA, 2014.

44. Kleinman, S.; Copp, M.A.; Henderson, K.A. Qualitatively different: Teaching fieldwork to graduate students. J. Contemp. Ethnogr. 1997, 25, 469-499. [CrossRef]

45. Braun, V.; Clarke, V. Using thematic analysis in psychology. Qual. Res. Psychol. 2006, 3, 77-101. [CrossRef]

46. Charmaz, K. Ground theory. In Rethinking Methods in Psychology; Smith, J., Harroe, R., Van Langenhov, L., Eds.; Sage: London, UK, 1995; pp. 27-49.

47. Nagy Hesse-Biber, S.; Leavy, P. Approaches to Qualitative Research: A Reader on Theory and Practice; Oxford University Press: New York, NY, USA, 2004; p. 412.

48. Gossett, A.; Mirza, M.; Barnds, A.K.; Feidt, D. Beyond access: A case study on the intersection between accessibility, sustainability, and universal design. Disabil. Rehabil. Assist. Technol. 2009, 4, 439-450. [CrossRef]

49. Hodson, R. Dignity at Work; Cambridge University Press: Cambridge, UK, 2001.

50. Bolton, S. Dimensions of Dignity at Work; Butterworth-Heinemann: Burlington, MA, USA, 2007.

51. Tippett, J.; How, F. Where to lean the ladder of participation: A normative heuristic for effective coproduction processes. TPR Town Plan. Rev. 2020, 91, 109-132. [CrossRef] 
52. Burnett, J.; Baker, H.B. Assessing the travel-related behaviors of the mobility-disabled consumer. J. Travel Res. 2001, 40, 4-8. [CrossRef]

53. Bascom, G.W.; Christensen, K.M. The impacts of limited transportation access on persons with disabilities' social participation. J. Transp. Health 2017, 7, 227-234. [CrossRef]

54. Tyler, N. Safety accessibility and sustainability: The importance of micro-scale outcomes to an equitable design of transport systems. IATSS Res. 2017, 41, 57-65. [CrossRef]

55. Dorozenko, K.P.; Roberts, L.D.; Bishop, B. The identities and social roles of people with an intellectual disability: Challenging dominant cultural worldviews, values and mythologies. Disabil. Soc. 2015, 30, 1345-1364. [CrossRef]

56. Danieli, A.; Woodhams, C. Emancipatory research methodology and disability: A critique. Int. J. Soc. Res. Methodol. 2005, 8, 281-296. [CrossRef]

57. Eide, A.H.; Loeb, M. Counting disabled people: Historical perspectives and the challenges of disability statistics. In Disability in the Global South; Springer: Cham, Switzerland, 2016; pp. 51-68.

Publisher's Note: MDPI stays neutral with regard to jurisdictional claims in published maps and institutional affiliations.

(C) 2020 by the authors. Licensee MDPI, Basel, Switzerland. This article is an open access article distributed under the terms and conditions of the Creative Commons Attribution (CC BY) license (http://creativecommons.org/licenses/by/4.0/). 